\title{
Structure and dynamics of the SARS-CoV-2 envelope protein monomer
}

2

3 Alexander Kuzmin ${ }^{1}$, Philipp Orekhov ${ }^{1,2}$, Roman Astashkin ${ }^{1,3}$, Valentin Gordeliy ${ }^{1,3,4,5}$, Ivan Gushchin ${ }^{1, *}$

4

$5 \quad{ }^{1}$ Research Center for Molecular Mechanisms of Aging and Age-related Diseases, Moscow Institute of

6 Physics and Technology, Dolgoprudny, Russia

$7 \quad{ }^{2}$ Faculty of Biology, M.V. Lomonosov Moscow State University, Moscow, Russia

$8{ }^{3}$ Institut de Biologie Structurale (IBS), Université Grenoble Alpes, CEA, CNRS, Grenoble, France

$9 \quad{ }^{4}$ Institute of Biological Information Processing (IBI-7: Structural Biochemistry), Forschungszentrum

10 Jülich GmbH, Jülich, Germany

$11{ }^{5}$ JuStruct: Jülich Center for Structural Biology, Forschungszentrum Jülich GmbH, Jülich, Germany.

12

13 E-mail for correspondence: ivan.gushchin@phystech.edu

14

15 


\section{Abstract}

Coronaviruses, especially SARS-CoV-2, present an ongoing threat for human wellbeing.

18 Consequently, elucidation of molecular determinants of their function and interaction with host is an

19 important task. Whereas some of the coronaviral proteins are extensively characterized, others remain

understudied. Here, we use molecular dynamics simulations to analyze the structure and dynamics of the SARS-CoV-2 envelope (E) protein (a viroporin) in the monomeric form. The protein consists of the hydrophobic $\alpha$-helical transmembrane domain (TMD) and amphiphilic $\alpha$-helices $\mathrm{H} 2$ and $\mathrm{H} 3$, connected by flexible linkers. We show that TMD has a preferable orientation in the membrane, while $\mathrm{H} 2$ and $\mathrm{H} 3$ reside at the membrane surface. Orientation of $\mathrm{H} 2$ is strongly influenced by palmitoylation of cysteines Cys40, Cys43 and Cys44. Glycosylation of Asn66 affects the orientation of H3. We also observe that the E protein both generates and senses the membrane curvature, preferably localizing with the Cterminus at the convex regions of the membrane. This may be favorable for assembly of the $\mathrm{E}$ protein oligomers, whereas induction of curvature may facilitate budding of the viral particles. The presented results may be helpful for better understanding of the function of coronaviral E protein and viroporins in general, and for overcoming the ongoing SARS-CoV-2 pandemic.

31 


\section{Introduction}

are enveloped viruses with a positive sense, single-stranded RNA genome of $\sim 30 \mathrm{~kb}$, one of the largest

among RNA viruses [1]. CoVs infect birds and mammals, causing a variety of fatal diseases. They can

also infect humans and cause diseases ranging from the common cold to acute respiratory distress syndrome. Highly pathogenic human coronaviruses include Severe Acute Respiratory Syndrome (SARS)-CoV, Middle Eastern Respiratory Syndrome (MERS)-CoV and SARS-CoV-2 [2,3]. The outbreaks of SARS-CoV in 2002/3 and MERS-CoV in 2012 led to epidemics. SARS-CoV-2 emerged at the end of December, 2019 causing a pandemic of the coronavirus disease 2019 (COVID-19), which is a novel life-threatening form of atypical pneumonia [4]. of the spread of infections, and treatment of patients who have already contracted the disease. Development of both kinds of strategies benefits greatly from understanding the virus physiology, and in particular the structure and function of viral proteins. Structural biology studies of SARS-CoV-2 have seen rapid progress since the beginning of the pandemic [5]. Whereas most of the key information was obtained using experimental techniques, such as cryoelectron microscopy, X-ray crystallography or NMR, computational approaches were key for some of the findings [6,7]. Among the most notable examples are detailed simulations of dynamics of the most important viral proteins $[6,8,9]$ or even the whole virion [10], early generation of atomic models for all SARS-CoV-2 proteins [11], and highthroughput virtual ligand screening of viral protease inhibitors [12,13].

The genomes of all coronaviruses encode four major structural proteins: the spike (S) protein, nucleocapsid $(\mathrm{N})$ protein, membrane $(\mathrm{M})$ protein, and the envelope $(\mathrm{E})$ protein [14]. The S protein is involved in the host recognition, attachment and cell fusion. The $\mathrm{N}$ protein is involved in packaging of the RNA genome and formation of the nucleocapsid. The M protein directs the assembly process of virions through interactions with the other structural proteins and defines the shape of the viral envelope. The E protein is possibly the most mysterious of them since it is associated with the assembly of virions, effective virion transfer along the secretory pathway as well as a reduced stress response by the host cell. Generally, it promotes virus fitness and pathogenesis [15]. 

which have at least one helical transmembrane domain (TMD) and a long amphiphilic region comprising one or two $\alpha$-helices at the C-terminus [16,17]. SARS-CoV-2 E protein consists of 75 amino acids, and its sequence is $95 \%$ and $36 \%$ identical to those of SARS-CoV and MERS-CoV E proteins, respectively. Given the sequence identity and the available data, SARS-CoV and SARS-CoV-2 E proteins appear to be very similar in their structure and function, and most of the findings about the former proteins likely apply to the latter as well. The general properties of the SARS-CoV-2 E protein presumably match those of other coronaviral E proteins.

It was shown previously that E proteins may undergo post-translational modifications (PTMs) $[16,17]$, but the role of these modifications is still not fully clear. The prominent examples of other viral proteins that may be also modified by palmitoylation are the coronaviral $\mathrm{S}$ protein, haemagglutinin (HA) protein of the influenza virus, Env proteins of retroviruses and filoviruses, and vaccinia virus 37 kDa major envelope antigen (p37) [18-21]. Some results indicate that conserved cysteines SARS-CoV E and, presumably, their palmitoylation are functionally important for stability of the E protein and the overall virus production [22,23]. On the other hand, glycosylation shields viral proteins from recognition by immune system $[24,25]$. It is closely linked to the protein topology as modification can happen only in the lumen of endoplasmic reticulum. SARS-CoV and SARS-CoV-2 E proteins are predominantly inserted in the membrane with their C-termini in the cytoplasm and are not modified [22,26,27]; a minor fraction can be glycosylated under certain non-native conditions [22,27]. The role of this possible glycosylation of E proteins is not clear [17].

Only a small portion of the E protein expressed during infection is incorporated into the virion envelope; the rest is localized at the intracellular trafficking endoplasmic reticulum (ER)-Golgi region and mostly at the intermediate compartment between ER and Golgi apparatus (ERGIC) [23,26,28-31]. ERGIC is composed of tubulovesicular membrane clusters, with many curved membrane regions [32]. CoVs assemble and bud at the ERGIC, where the E protein may induce membrane curvature or aid in membrane scission $[16,17]$. Indeed, various recombinant CoVs lacking the gene for E exhibit an aberrant morphology, from which it can be concluded that the function of $\mathrm{E}$ is to induce membrane curvature of the viral envelope, thus allowing $\mathrm{CoV}$ particles to acquire their characteristic spherical 
shape and morphology $[29,33,34]$. E protein was also shown to colocalize and interact with the $\mathrm{M}$ and S proteins [38] and, together with M, affects processing, maturation and localization of S [28]. Finally, it can also interact with cellular proteins Bcl-xL [39], PALS1 [40,41] and others such as CWC27, AP3B1, ZC3H18, SLC44A2, BRD2 and BRD4 [42]. be inhibited by hexamethylene amiloride (HMA) and amantadine [47-51]. Similar small proteins (60120 residues), which oligomerize and form hydrophilic transmembrane pores or channels and disrupt a number of physiological characteristics of the cell, are called viroporins [52]. They are known to contribute to release of infectious enveloped virus particles from infected cells and/or to facilitate the penetration of the viruses into the cell. The most famous representative viroporins of highly pathogenic RNA viruses are human immunodeficiency virus type 1 (HIV-1) Viral protein $\mathrm{U}(\mathrm{Vpu})$ protein, hepatitis C virus p7 protein and influenza A virus matrix protein 2 (M2), which are involved in diverse processes such as virus entry, trafficking, assembly, inflammation and apoptosis [52]. The significant contribution of viroporins to the life cycle of viruses makes them a target for therapeutic interventions. In particular, M2 can be targeted by an FDA-approved inhibitor rimantadine [53]. Investigations have shown that SARS-CoV viruses, in which the channel activity is inhibited, were much less infectious and pathogenic [54].

Currently, several experimental structures of the E protein fragments are available $[45,48,50,55,56]$. In particular, it was shown that the protein contains a TM $\alpha$-helix and one (when in monomeric form and in detergent, [55]) or two (when in pentameric form, [56]) amphipathic $\alpha$-helices.

111 Yet, experimental structure of the full-length wild type protein is not available at the moment, and the 112 influence of PTMs on it hasn't been studied. Moreover, there is little data on behavior of monomeric E 113 protein prior to its assembly into pentameric channels. In the present study, we applied molecular 114 dynamics to study the behavior of monomeric E protein from SARS-CoV-2 and identified the effects of PTMs on the protein behavior. We have also observed that the protein induces curvature in the membranes, and is attracted to the curved regions. These findings may be helpful in development of

117 anti-SARS-CoV-2 medications, and for understanding the function of viroporins in general. 


\section{Results}

E protein from SARS-CoV-2 is a 75 amino acid-long protein that may be palmitoylated and

CG simulations are known to faithfully reproduce the major physicochemical properties of the studied macromolecules while providing a considerable speedup compared to atomistic simulations $[57,58]$. the helices $\mathrm{H} 2$ and $\mathrm{H} 3$ relative to each other and TMD near the membrane surface.

Atomistic simulations are considerably more computationally demanding, and thus the exhaustive sampling of the conformational space can take a prohibitively long time. Consequently, we simulated a number of atomistic trajectories starting from representative conformations from the CG simulation. We divided the CG trajectory snapshots into four clusters, and used the centroids of the clusters as the starting structures for atomistic simulations. For each starting structure, we obtained six trajectories of the E protein: three with the protein embedded in the model membrane containing POPC, and three with the membrane mimicking the natural ERGIC membrane (50\% POPC, 25\% POPE, 10\% POPI, 5\% POPS, $10 \%$ cholesterol). No qualitative differences were observed between the simulations conducted in these membranes. Overall, PCA shows that the atomistic simulations correspond to the CG simulation and display roughly the same conformational space available to the E protein 


\section{Position of the E protein elements relative to the membrane}

Figure 4 shows the average positions of the secondary structure elements of the E protein

148 relative to the membrane surface. In all of the simulations, the TMD remained embedded in the

149 membrane. $\mathrm{H} 2$ is deeply buried in the lipid headgroup region, whereas $\mathrm{H} 3$ is slightly removed from the

150 membrane border, while still remaining in contact with it. In some atomistic trajectories, partial

151 unbinding of $\mathrm{H} 3$ from the membrane is observed (Figure S3).

Interestingly, TMD, despite being a single transmembrane $\alpha$-helix, has a preferable orientation

in the membrane (Figure 5). It is tilted at the angle of $25-40^{\circ}$ in all of the simulations and has a strong

154 orientational (azimuthal) preference, with phenylalanines Phe20, Phe23 and Phe26 oriented towards the

N-terminal side. No robust effects of post-translational modifications on the orientation of TMD were observed (Table 1).

$\mathrm{H} 2$, as an amphipathic helix, also has a preferred orientation (Figure 6). Palmitoylation of the

three cysteines, Cys40, Cys43 and Cys44, in different patterns changes the physicochemical properties orientation is observed when Cys40 and Cys44 are palmitoylated simultaneously: the helix is rotated by $\sim 32.2^{\circ}$ relative to its position in the unmodified protein. Other palmitoylated variants have intermediate orientations; the effects of palmitoylation of the three cysteine residues are not additive (Table 1).

Position of H3 was not significantly affected by palmitoylation. Yet, glycosylation of Asn66 had a pronounced effect on its dynamics (Figure 7). In the unmodified protein, we observed two major orientations of H3: the first one with the hydrophobic residues Val62 and Leu65 facing the membrane, and the less frequent orientation almost completely opposite to it, with $\mathrm{H} 3$ stacking with $\mathrm{H} 2$ while being due to the potential steric conflict between the sugar moiety and H2 (Figure 7A,D); the helix was also slightly rotated in the most frequent orientation (Figure 7A,E). 
174 observed in larger systems containing four E protein monomers in opposite orientations (Figure S4) and

175 in atomistic simulations (Figure S5). Presumably, the curvature is induced by the amphipathic helices

176 that embed into the adjacent leaflet and expand it.

177 To check whether the curvature is indeed induced by $\mathrm{H} 2$ and $\mathrm{H} 3$, we conducted additional 178 simulations of artificial proteins consisting of only TMD or only H2 and H3 (Figure 8B,C). Isolated 179 TMD was tilted in a way similar to that observed in the simulations of the full-length protein. The membrane was perturbed and thinned near the $\alpha$-helix (Figure 8B), presumably because of the polar residues on the respective sides (Glu8, Thr9, Thr11, Asn15, Ser16 at the N-terminal side, Thr30, Thr35

182 at the $\mathrm{C}$-terminal side). Isolated $\mathrm{H} 2$ and $\mathrm{H} 3$ curved the membrane in the same way as the full-length 183 protein (Figure 8C). Thus, we conclude that the structural elements responsible for curvature induction 184 by the E protein are the amphipathic helices of the C-terminal domain.

\section{Dynamics of the E protein within curved membranes}

Having observed the induction of curvature by the E protein, we were also interested to check whether it has a preferable position in membranes that are already curved, such as the native ER, Golgi and ERGIC membranes, especially during the budding of VLPs. As a test system, we used artificially buckled membranes [59-62]. Irrespective of the starting positions, E protein monomers redistribute in

190 the membranes so that the C-termini localize to the convex regions (Figure 9). The effect was observed 191 both in the membranes buckled in a single direction (non-zero mean curvature, zero Gaussian curvature, 192 Figure 9A) and in the membranes buckled in both directions (positive Gaussian curvature, Figure 9B).

193 Thus, we conclude that the monomeric E protein is curvature-sensitive. 


\section{Discussion}

Coronaviruses have relatively large genomes harboring tens of different genes. Understanding

198 of their structures could help in development of efficient antiviral measures. Yet some of the $\mathrm{CoV}$ 199 proteins are transmembrane, and some contain intrinsically disordered regions [63], at least until they become a part of a larger assembly. E protein has both properties: it has a TM segment, and it lacks tertiary structure in the monomeric form, becoming mostly ordered in the pentameric assembly. Its flexibility and numerous PTMs pose many problems for experimental studies, especially of the monomeric E protein. However, because it is small, and its properties are governed by basic physicochemical principles, it is a good subject for simulations.

Our results show that monomeric SARS-CoV-2 envelope protein has rich conformational dynamics strongly affected by post-translational modifications. The protein is organized as an $\alpha$-helical TMD and two amphipathic $\alpha$-helices $\mathrm{H} 2$ and $\mathrm{H} 3$, flanked by short disordered $\mathrm{N}$ - and $\mathrm{C}$-termini. Whereas TMD is rigid and remains $\alpha$-helical throughout the trajectories, helices $\mathrm{H} 2$ and $\mathrm{H} 3$ may partially unfold. TMD, $\mathrm{H} 2$ and $\mathrm{H} 3$ mostly move freely relative to each other, so the monomeric E protein can be considered an intrinsically disordered protein. Yet, all of its $\alpha$-helices have preferred orientations relative to the membrane.

The TM $\alpha$-helix of the E protein is relatively long (28 amino acids, $\sim 43 \AA$ ), and there is a mismatch between the length of its hydrophobic segment and the thickness of the hydrophobic region of the relevant membranes. Tilting of TM helices is a common mechanism for accommodating such mismatch [64-68]. Accordingly, we find that E protein TMD is tilted at $25-40^{\circ}$, similarly to TMD in pentameric E protein [56] and in other viroporins (Table S2). It also has a preferred azimuthal rotation

217 angle, similarly to WALP peptides $[69,70]$, for which the results obtained with MD simulations were

218 found to correspond well to those obtained in experiments [71]. However, the rotation angle of TMD 219 in a free E protein monomer is opposite to that in the E protein pentamer. This is likely a consequence of the polar residues such as Glu8, Thr9, Thr11, Asn15, Ser16, Thr30 and Thr35 preferably facing the solvent in the monomer and interior of the channel in the pentamer. on post-translational modifications. Previously, it was shown that palmitoylation is important for E 
protein stability and overall assembly of VLPs, whereas the role of glycosylation is more elusive [17].

Yet, experimental studies of the effects of PTMs on protein structure are hindered by difficulties in obtaining homogeneous samples with a desired PTM pattern; in vivo, palmitoylation is likely to be stochastic [72]. The proteins may be mutated to abolish the particular PTM, however this may also introduce unintended side effects. On the other hand, simulations allow for easier targeted testing of different defined combinations of PTMs. to alanines, Asn66 was missing ( $\mathrm{Li}$ et al 2014, Surya et al 2018). SARS-CoV-2 construct was even shorter (residues 8-38) and did not include the residues that could be modified (Mandala et al, 2020). Previous computational studies of the E protein also did not focus on the effects of PTM $[11,73,74]$. In this work, we found that the average orientation of $\mathrm{H} 2$ is strongly dependent on palmitoylation pattern, as the acyl chains act as anchors on the respective $\mathrm{H} 2$ cysteines and bring them closer to the membrane core. On the other hand, positioning of $\mathrm{H} 3$ is affected by glycosylation as the glycan acts as a buoy on $\mathrm{H} 3$ and prevents its interaction with $\mathrm{H} 2$. However, most or all of the E proteins in vivo are probably not glycosylated [27], so the possible role of this modification remains unclear. While we did not study the E protein in pentameric form, we believe that PTMs are likely to elicit effects in the assembled oligomers similar to those that we observe in monomers. In the last part of our work, we focused on interactions of the E protein with curved membranes. Overall, membrane curvature is an important factor in cell physiology [75], being both generated and sensed by the major membrane constituents: lipids and proteins [76,77]. Some amphipathic $\alpha$-helices are known to generate curvature by creating the area difference between the two leaflets of the bilayer $[78,79]$ or to act as curvature sensors $[80,81]$.

Along with experiments, molecular dynamics simulations have also been fundamental in studies of curved membranes [57]. Earlier, simulations have been used to study repartitioning of both lipids and proteins in naturally and artificially curved membranes [59-62]; a prominent example is enrichment of cholesterol in the regions with negative curvature [59,61]. Another example is the influenza A M2 protein, for which both experiments and simulations show that its amphiphilic $\alpha$-helix 

can act as a curvature sensor [62].

We have also found that the monomeric E protein can act as a curvature sensor and localize with the Cterminus at the convex regions of the membrane. Given that the C-terminus of $\mathrm{E}$ is oriented towards the cytoplasm [27], the protein is likely to localize at the VLP budding sites and promote VLP budding.

260 Concentration in these curved areas may promote formation of pentameric channels. The assembled 261 channels are also likely to be curvature-sensitive due to their umbrella-like shape $[11,56]$. On the other hand, E protein is expected to be depleted at the concave inner surface of the VLP, in agreement with experimental data $[23,26,28-31]$.

\section{Conclusions}

Our simulations show that the SARS-CoV-2 E protein in monomeric form has rich structural dynamics. They also highlight the importance of considering the effects of palmitoylation and glycosylation on the protein's structure. The obtained results are in accordance with experimental observations, while providing a detailed description of the E protein structure. Finally, our work showcases MD simulations as an important complementary technique allowing comprehensive inquiry in the case where the experiment is complicated: when the protein is partially disordered and may be differentially post-translationally modified.

273 


\section{Acknowledgements}

277 gratefully acknowledge the computing time granted through JARA on the supercomputer JURECA at

278 Forschungszentrum Jülich. I.G. was supported by the Ministry of Science and Higher Education of the 279 Russian Federation (agreement \#075-00337-20-03, project FSMG-2020-0003). V.G. and R.A. were 280 supported by the Commissariat à l'Energie Atomique et aux Energies Alternatives (Institut de Biologie 281 Structurale) - Helmholtz-Gemeinschaft Deutscher Forschungszentren (Forschungszentrum Jülich) 282 Special Terms and Conditions 5.1 specific agreement.

\section{Author contributions}

I.G. designed and supervised the project; P.O. and V.G. helped with the project design; manuscript; P.O., R.A. and V.G. helped with data analysis and manuscript preparation.

\section{Competing interests}

The authors declare no competing interests.

\section{Additional information}

Supplementary information is available. 


\section{Materials and methods}

As a starting structure for simulations of the monomeric SARS-CoV-2 E protein, we used the

297 model prepared by Heo and Feig [11] (https://github.com/feiglab/sars-cov-2-

298 proteins/blob/master/Membrane/E_protein.pdb, accessed on September $\left.1^{\text {st }}, 2020\right)$. Atomistic structure

was converted into coarse-grained Martini 3 representation [84] using martinize. DSSP [85,86] was

POPI were charged. The membranes were solvated with water; counter ions were added to neutralize energy minimized using the steepest descent method, equilibrated and simulated using GROMACS 2019.5 (AA) and GROMACS 2020.1 (CG) [91]. To generate the buckled membranes, we compressed the bilayers in the $X$-dimension until reaching the desired strain by fixing the box size in these

311 dimensions, while the membrane pressure coupling was turned off in the $X-Y$ lateral dimensions.

$3142 \mathrm{fs}$, at a reference temperature of 323 and $310 \mathrm{~K}$, respectively, and at a reference pressure of 1 bar.

315 Temperature was coupled using velocity rescale [92] and Nosé-Hoover [93] thermostats with coupling 316 constant of $1 \mathrm{ps}^{-1}$, respectively. Pressure was coupled with semiisotropic Parrinello-Rahman barostat 317 [94] with relaxation time of 12 or 5 ps, respectively. nonpolarizable water and optimized parameters for palmitoylated cysteines [95] and glycosylated asparagine [96] where needed. The center of mass of the reference structure was scaled with the scaling 
matrix of the pressure coupling. The non-bonded pair list was updated every 20 steps with the cutoff of $1.1 \mathrm{~nm}$. Potentials shifted to zero at the cutoff of $1.1 \mathrm{~nm}$ and a reaction-field potential with $\varepsilon_{\mathrm{rf}}=\infty$ were used for treatment of the van der Waals and electrostatics interactions.

\section{AA simulations}

AA simulations were conducted using the CHARMM36m force field [97]. The covalent bonds to hydrogens were constrained using the LINCS algorithm [98]. The non-bonded pair list was updated every 20 steps with the cutoff of $1.2 \mathrm{~nm}$. Force-based switching function with the switching range of 1.0-1.2 nm and particle mesh Ewald (PME) method with $0.12 \mathrm{~nm}$ Fourier grid spacing and $1.2 \mathrm{~nm}$ cutoff were used for treatment of the van der Waals and electrostatics interactions. The simulations were performed using JURECA [99].

\section{Analysis}

VMD [100] and in-house scripts were used for analysis of the TMD tilt angle $(\alpha)$ and rotational (azimuthal) angles $(\beta, \varphi, \psi)$ of the TMD, $\mathrm{H} 2$ and $\mathrm{H} 3$. The tilt angle was defined as the angle between the TMD helix axis and the normal to the membrane (axis Z). The rotational angle was defined as the angle between the $\mathrm{C}_{\alpha}$ radial vector of a reference residue (Phe23, Cys43, Asn66) and the X-Z plane; the helix was aligned so that its axis was in the $\mathrm{X}-\mathrm{Z}$ plane (Figures 5-7). We used the Ward's method from MDTraj [101] to group the dataset into 4 clusters based on pairwise RMSD of coordinates of backbone particles. Density distributions of TMD, H2 and H3 atoms were calculated using the density tool from GROMACS. The secondary structure in the E protein was monitored using the Timeline plugin (version 2.3) for VMD[100]. PCA was performed on the positions of the $\mathrm{C}_{\alpha}$ atoms and backbone particles using the covar and anaeig tools from GROMACS. Average positions of the membrane boundaries were calculated using g_lomepro, version 1.0.2 [102]. 


\section{References}

346

347

348

349

350

351

352

353

354

355

356

357

358

359

360

361

362

363

364

365

366

367

368

369

370

371

372

373

374

375

376

377

378

379

380

381

382

383

384

385

386

387

388

389

390

391

392

393

394

395

396

397

398

[1] A.R. Fehr, S. Perlman, Coronaviruses: An Overview of Their Replication and Pathogenesis, in: H.J. Maier, E. Bickerton, P. Britton (Eds.), Coronaviruses: Methods and Protocols, Springer, New York, NY, 2015: pp. 1-23. https://doi.org/10.1007/978-1-4939-2438-7_1.

[2] A.E. Gorbalenya, S.C. Baker, R.S. Baric, R.J. de Groot, C. Drosten, A.A. Gulyaeva, B.L. Haagmans, C. Lauber, A.M. Leontovich, B.W. Neuman, D. Penzar, S. Perlman, L.L.M. Poon, D.V. Samborskiy, I.A. Sidorov, I. Sola, J. Ziebuhr, Coronaviridae Study Group of the International Committee on Taxonomy of Viruses, The species Severe acute respiratory syndrome-related coronavirus : classifying 2019-nCoV and naming it SARS-CoV-2, Nature Microbiology. 5 (2020) 536-544. https://doi.org/10.1038/s41564-020-0695-z.

[3] J. Cui, F. Li, Z.-L. Shi, Origin and evolution of pathogenic coronaviruses, Nature Reviews Microbiology. 17 (2019) 181-192. https://doi.org/10.1038/s41579-018-0118-9.

[4] B. Hu, H. Guo, P. Zhou, Z.-L. Shi, Characteristics of SARS-CoV-2 and COVID-19, Nature Reviews Microbiology. (2020) 1-14. https://doi.org/10.1038/s41579-020-00459-7.

[5] M. Bárcena, C.O. Barnes, M. Beck, P.J. Bjorkman, B. Canard, G.F. Gao, Y. Gao, R. Hilgenfeld, G. Hummer, A. Patwardhan, G. Santoni, E.O. Saphire, C. Schaffitzel, S.L. Schendel, J.L. Smith, A. Thorn, D. Veesler, P. Zhang, Q. Zhou, Structural biology in the fight against COVID-19, Nature Structural \& Molecular Biology. 28 (2021) 2-7. https://doi.org/10.1038/s41594-020-00544-8.

[6] P.R. Arantes, A. Saha, G. Palermo, Fighting COVID-19 Using Molecular Dynamics Simulations, ACS Cent. Sci. 6 (2020) 1654-1656. https://doi.org/10.1021/acscentsci.0c01236.

[7] A.J. Mulholland, R.E. Amaro, COVID19 - Computational Chemists Meet the Moment, J. Chem. Inf. Model. 60 (2020) 5724-5726. https://doi.org/10.1021/acs.jcim.0c01395.

[8] M.I. Zimmerman, J.R. Porter, M.D. Ward, S. Singh, N. Vithani, A. Meller, U.L. Mallimadugula, C.E. Kuhn, J.H. Borowsky, R.P. Wiewiora, M.F.D. Hurley, A.M. Harbison, C.A. Fogarty, J.E. Coffland, E. Fadda, V.A. Voelz, J.D. Chodera, G.R. Bowman, SARS-CoV2 Simulations Go Exascale to Capture Spike Opening and Reveal Cryptic Pockets Across the Proteome, BioRxiv. (2020) 2020.06.27.175430. https://doi.org/10.1101/2020.06.27.175430.

[9] L. Casalino, Z. Gaieb, J.A. Goldsmith, C.K. Hjorth, A.C. Dommer, A.M. Harbison, C.A. Fogarty, E.P. Barros, B.C. Taylor, J.S. McLellan, E. Fadda, R.E. Amaro, Beyond Shielding: The Roles of Glycans in the SARS-CoV-2 Spike Protein, ACS Cent. Sci. 6 (2020) 1722-1734. https://doi.org/10.1021/acscentsci.0c01056.

[10] A. Yu, A.J. Pak, P. He, V. Monje-Galvan, L. Casalino, Z. Gaieb, A.C. Dommer, R.E. Amaro, G.A. Voth, A multiscale coarse-grained model of the SARS-CoV-2 virion, Biophysical Journal. 0 (2020). https://doi.org/10.1016/j.bpj.2020.10.048.

[11] L. Heo, M. Feig, Modeling of Severe Acute Respiratory Syndrome Coronavirus 2 (SARSCoV-2) Proteins by Machine Learning and Physics-Based Refinement, BioRxiv. (2020) 2020.03.25.008904. https://doi.org/10.1101/2020.03.25.008904.

[12] J. Chodera, A.A. Lee, N. London, F. von Delft, Crowdsourcing drug discovery for pandemics, Nature Chemistry. 12 (2020) 581-581. https://doi.org/10.1038/s41557-020-0496-2.

[13] T.C.M. Consortium, H. Achdout, A. Aimon, E. Bar-David, H. Barr, A. Ben-Shmuel, J. Bennett, M.L. Bobby, J. Brun, B. Sarma, M. Calmiano, A. Carbery, E. Cattermole, J.D. Chodera, A. Clyde, J.E. Coffland, G. Cohen, J. Cole, A. Contini, L. Cox, M. Cvitkovic, A. Dias, A. Douangamath, S. Duberstein, T. Dudgeon, L. Dunnett, P.K. Eastman, N. Erez, M. Fairhead, D. Fearon, O. Fedorov, M. Ferla, H. Foster, R. Foster, R. Gabizon, P. Gehrtz, C. Gileadi, C. Giroud, W.G. Glass, R. Glen, I. Glinert, M. Gorichko, T. Gorrie-Stone, E.J. Griffen, J. Heer, M. Hill, S. Horrell, M.F.D. Hurley, T. Israely, A. Jajack, E. Jnoff, T. John, A.L. Kantsadi, P.W. Kenny, J.L. Kiappes, L. Koekemoer, B. Kovar, T. Krojer, A.A. Lee, B.A. Lefker, H. Levy, N. London, P. Lukacik, H.B. Macdonald, B. MacLean, T.R. Malla, T. Matviiuk, W. McCorkindale, S. Melamed, O. Michurin, H. Mikolajek, A. Morris, G.M. Morris, M.J. Morwitzer, D. Moustakas, J.B. Neto, V. Oleinikovas, G.J. Overheul, D. Owen, R. Pai, J. Pan, N. Paran, B. Perry, M. Pingle, J. Pinjari, B. Politi, A. Powell, V. Psenak, R. Puni, V.L. Rangel, R.N. Reddi, S.P. Reid, E. Resnick, M.C. Robinson, R.P. Robinson, D. Rufa, C. Schofield, A. Shaikh, J. Shi, K. Shurrush, A. Sittner, R. Skyner, A. Smalley, M.D. Smilova, J. 
Spencer, C. Strain-Damerell, V. Swamy, H. Tamir, R. Tennant, A. Thompson, W. Thompson, S. Tomasio, A. Tumber, I. Vakonakis, R.P. van Rij, F.S. Varghese, M. Vaschetto, E.B. Vitner, V. Voelz, A. von Delft, F. von Delft, M. Walsh, W. Ward, C. Weatherall, S. Weiss, C.F. Wild, M. Wittmann, N. Wright, Y. Yahalom-Ronen, D. Zaidmann, H. Zidane, N. Zitzmann, COVID Moonshot: Open Science Discovery of SARS-CoV-2 Main Protease Inhibitors by Combining Crowdsourcing, High-Throughput Experiments, Computational Simulations, and Machine Learning, BioRxiv. (2020) 2020.10.29.339317. https://doi.org/10.1101/2020.10.29.339317.

[14] P.S. Masters, The Molecular Biology of Coronaviruses, in: Advances in Virus Research, Academic Press, 2006: pp. 193-292. https://doi.org/10.1016/S0065-3527(06)66005-3.

[15] J.L. Nieto-Torres, M.L. DeDiego, C. Verdiá-Báguena, J.M. Jimenez-Guardeño, J.A. ReglaNava, R. Fernandez-Delgado, C. Castaño-Rodriguez, A. Alcaraz, J. Torres, V.M. Aguilella, L. Enjuanes, Severe Acute Respiratory Syndrome Coronavirus Envelope Protein Ion Channel Activity Promotes Virus Fitness and Pathogenesis, PLOS Pathogens. 10 (2014) e1004077. https://doi.org/10.1371/journal.ppat.1004077.

[16] T.R. Ruch, C.E. Machamer, The Coronavirus E Protein: Assembly and Beyond, Viruses. 4 (2012) 363-382. https://doi.org/10.3390/v4030363.

[17] D. Schoeman, B.C. Fielding, Coronavirus envelope protein: current knowledge, Virology Journal. 16 (2019) 69. https://doi.org/10.1186/s12985-019-1182-0.

[18] C.M. Petit, V.N. Chouljenko, A. Iyer, R. Colgrove, M. Farzan, D.M. Knipe, K.G. Kousoulas, Palmitoylation of the cysteine-rich endodomain of the SARS-coronavirus spike glycoprotein is important for spike-mediated cell fusion, Virology. 360 (2007) 264-274. https://doi.org/10.1016/j.virol.2006.10.034.

[19] Y. Fujiwara, H.X. Kondo, M. Shirota, M. Kobayashi, K. Takeshita, A. Nakagawa, Y. Okamura, K. Kinoshita, Structural basis for the membrane association of ankyrinG via palmitoylation, Scientific Reports. 6 (2016) 23981. https://doi.org/10.1038/srep23981.

[20] J. Sobocińska, P. Roszczenko-Jasińska, A. Ciesielska, K. Kwiatkowska, Protein Palmitoylation and Its Role in Bacterial and Viral Infections, Front. Immunol. 8 (2018). https://doi.org/10.3389/fimmu.2017.02003.

[21] J.A. Boscarino, H.L. Logan, J.J. Lacny, T.M. Gallagher, Envelope Protein Palmitoylations Are Crucial for Murine Coronavirus Assembly, Journal of Virology. 82 (2008) 2989-2999. https://doi.org/10.1128/JVI.01906-07.

[22] Q. Yuan, Y. Liao, J. Torres, J.P. Tam, D.X. Liu, Biochemical and functional characterization of the membrane association and membrane permeabilizing activity of the severe acute respiratory syndrome coronavirus envelope protein, Virology. 349 (2006) 264-275. https://doi.org/10.1016/j.virol.2006.01.028.

[23] L.A. Lopez, A.J. Riffle, S.L. Pike, D. Gardner, B.G. Hogue, Importance of Conserved Cysteine Residues in the Coronavirus Envelope Protein, Journal of Virology. 82 (2008) 3000-3010. https://doi.org/10.1128/JVI.01914-07.

[24] O.C. Grant, D. Montgomery, K. Ito, R.J. Woods, Analysis of the SARS-CoV-2 spike protein glycan shield reveals implications for immune recognition, Scientific Reports. 10 (2020) 14991. https://doi.org/10.1038/s41598-020-71748-7.

[25] J.D. Marth, P.K. Grewal, Mammalian glycosylation in immunity, Nature Reviews Immunology. 8 (2008) 874-887. https://doi.org/10.1038/nri2417.

[26] J.L. Nieto-Torres, M.L. DeDiego, E. Álvarez, J.M. Jiménez-Guardeño, J.A. Regla-Nava, M. Llorente, L. Kremer, S. Shuo, L. Enjuanes, Subcellular location and topology of severe acute respiratory syndrome coronavirus envelope protein, Virology. 415 (2011) 69-82. https://doi.org/10.1016/j.virol.2011.03.029.

[27] G. Duart, M.J. García-Murria, B. Grau, J.M. Acosta-Cáceres, L. Martínez-Gil, I. Mingarro, SARS-CoV-2 envelope protein topology in eukaryotic membranes, Open Biology. 10 (2020) 200209. https://doi.org/10.1098/rsob.200209.

[28] B. Boson, V. Legros, B. Zhou, E. Siret, C. Mathieu, F.-L. Cosset, D. Lavillette, S. Denolly, The SARS-CoV-2 envelope and membrane proteins modulate maturation and retention of the spike protein, allowing assembly of virus-like particles, Journal of Biological Chemistry. 296 (2021). https://doi.org/10.1074/jbc.RA120.016175. 
[29] J.R. Cohen, L.D. Lin, C.E. Machamer, Identification of a Golgi Complex-Targeting Signal in the Cytoplasmic Tail of the Severe Acute Respiratory Syndrome Coronavirus Envelope Protein, Journal of Virology. 85 (2011) 5794-5803. https://doi.org/10.1128/JVI.00060-11.

[30] M. Godet, R. L'Haridon, J.-F. Vautherot, H. Laude, TGEV corona virus ORF4 encodes a membrane protein that is incorporated into virions, Virology. 188 (1992) 666-675. https://doi.org/10.1016/0042-6822(92)90521-P.

[31] P. Venkatagopalan, S.M. Daskalova, L.A. Lopez, K.A. Dolezal, B.G. Hogue, Coronavirus envelope (E) protein remains at the site of assembly, Virology. 478 (2015) 75-85. https://doi.org/10.1016/j.virol.2015.02.005.

[32] C. Appenzeller-Herzog, H.-P. Hauri, The ER-Golgi intermediate compartment (ERGIC): in search of its identity and function, Journal of Cell Science. 119 (2006) 2173-2183. https://doi.org/10.1242/jcs.03019.

[33] J. Ortego, J.E. Ceriani, C. Patiño, J. Plana, L. Enjuanes, Absence of E protein arrests transmissible gastroenteritis coronavirus maturation in the secretory pathway, Virology. 368 (2007) 296-308. https://doi.org/10.1016/j.virol.2007.05.032.

[34] F. Fischer, C.F. Stegen, P.S. Masters, W.A. Samsonoff, Analysis of Constructed E Gene Mutants of Mouse Hepatitis Virus Confirms a Pivotal Role for E Protein in Coronavirus Assembly, Journal of Virology. 72 (1998) 7885-7894. https://doi.org/10.1128/JVI.72.10.78857894.1998.

[35] E. Corse, C.E. Machamer, The cytoplasmic tails of infectious bronchitis virus E and M proteins mediate their interaction, Virology. 312 (2003) 25-34. https://doi.org/10.1016/S00426822(03)00175-2.

[36] Y.-T. Tseng, S.-M. Wang, K.-J. Huang, C.-T. Wang, SARS-CoV envelope protein palmitoylation or nucleocapid association is not required for promoting virus-like particle production, Journal of Biomedical Science. 21 (2014) 34. https://doi.org/10.1186/1423-012721-34.

[37] E. Álvarez, M.L. DeDiego, J.L. Nieto-Torres, J.M. Jiménez-Guardeño, L. Marcos-Villar, L. Enjuanes, The envelope protein of severe acute respiratory syndrome coronavirus interacts with the non-structural protein 3 and is ubiquitinated, Virology. 402 (2010) 281-291. https://doi.org/10.1016/j.virol.2010.03.015.

[38] R. Xu, M. Shi, J. Li, P. Song, N. Li, Construction of SARS-CoV-2 Virus-Like Particles by Mammalian Expression System, Front. Bioeng. Biotechnol. 8 (2020). https://doi.org/10.3389/fbioe.2020.00862.

[39] Y. Yang, Z. Xiong, S. Zhang, Y. Yan, J. Nguyen, B. Ng, H. Lu, J. Brendese, F. Yang, H. Wang, X.-F. Yang, Bcl-xL inhibits T-cell apoptosis induced by expression of SARS coronavirus E protein in the absence of growth factors, Biochemical Journal. 392 (2005) 135143. https://doi.org/10.1042/BJ20050698.

[40] K.-T. Teoh, Y.-L. Siu, W.-L. Chan, M.A. Schlüter, C.-J. Liu, J.S.M. Peiris, R. Bruzzone, B. Margolis, B. Nal, The SARS coronavirus E protein interacts with PALS1 and alters tight junction formation and epithelial morphogenesis, Mol Biol Cell. 21 (2010) 3838-3852. https://doi.org/10.1091/mbc.E10-04-0338.

[41] A. Toto, S. Ma, F. Malagrinò, L. Visconti, L. Pagano, K. Stromgaard, S. Gianni, Comparing the binding properties of peptides mimicking the Envelope protein of SARS-CoV and SARS$\mathrm{CoV}-2$ to the PDZ domain of the tight junction-associated PALS1 protein, Protein Science. 29 (2020) 2038-2042. https://doi.org/10.1002/pro.3936.

[42] D.E. Gordon, G.M. Jang, M. Bouhaddou, J. Xu, K. Obernier, K.M. White, M.J. O’Meara, V.V. Rezelj, J.Z. Guo, D.L. Swaney, T.A. Tummino, R. Hüttenhain, R.M. Kaake, A.L. Richards, B. Tutuncuoglu, H. Foussard, J. Batra, K. Haas, M. Modak, M. Kim, P. Haas, B.J. Polacco, H. Braberg, J.M. Fabius, M. Eckhardt, M. Soucheray, M.J. Bennett, M. Cakir, M.J. McGregor, Q. Li, B. Meyer, F. Roesch, T. Vallet, A. Mac Kain, L. Miorin, E. Moreno, Z.Z.C. Naing, Y. Zhou, S. Peng, Y. Shi, Z. Zhang, W. Shen, I.T. Kirby, J.E. Melnyk, J.S. Chorba, K. Lou, S.A. Dai, I. Barrio-Hernandez, D. Memon, C. Hernandez-Armenta, J. Lyu, C.J.P. Mathy, T. Perica, K.B. Pilla, S.J. Ganesan, D.J. Saltzberg, R. Rakesh, X. Liu, S.B. Rosenthal, L. Calviello, S. Venkataramanan, J. Liboy-Lugo, Y. Lin, X.-P. Huang, Y. Liu, S.A. Wankowicz, M. Bohn, M. Safari, F.S. Ugur, C. Koh, N.S. Savar, Q.D. Tran, D. Shengjuler, S.J. Fletcher, M.C. O’Neal, 
Y. Cai, J.C.J. Chang, D.J. Broadhurst, S. Klippsten, P.P. Sharp, N.A. Wenzell, D. KuzuogluOzturk, H.-Y. Wang, R. Trenker, J.M. Young, D.A. Cavero, J. Hiatt, T.L. Roth, U. Rathore, A. Subramanian, J. Noack, M. Hubert, R.M. Stroud, A.D. Frankel, O.S. Rosenberg, K.A. Verba, D.A. Agard, M. Ott, M. Emerman, N. Jura, M. von Zastrow, E. Verdin, A. Ashworth, O. Schwartz, C. d'Enfert, S. Mukherjee, M. Jacobson, H.S. Malik, D.G. Fujimori, T. Ideker, C.S. Craik, S.N. Floor, J.S. Fraser, J.D. Gross, A. Sali, B.L. Roth, D. Ruggero, J. Taunton, T. Kortemme, P. Beltrao, M. Vignuzzi, A. García-Sastre, K.M. Shokat, B.K. Shoichet, N.J. Krogan, A SARS-CoV-2 protein interaction map reveals targets for drug repurposing, Nature. 583 (2020) 459-468. https://doi.org/10.1038/s41586-020-2286-9.

[43] C. Verdiá-Báguena, J.L. Nieto-Torres, A. Alcaraz, M.L. DeDiego, J. Torres, V.M. Aguilella, L. Enjuanes, Coronavirus E protein forms ion channels with functionally and structurallyinvolved membrane lipids, Virology. 432 (2012) 485-494. https://doi.org/10.1016/j.virol.2012.07.005.

[44] K. Parthasarathy, L. Ng, X. Lin, D.X. Liu, K. Pervushin, X. Gong, J. Torres, Structural Flexibility of the Pentameric SARS Coronavirus Envelope Protein Ion Channel, Biophysical Journal. 95 (2008) L39-L41. https://doi.org/10.1529/biophysj.108.133041.

[45] W. Surya, Y. Li, C. Verdià-Bàguena, V.M. Aguilella, J. Torres, MERS coronavirus envelope protein has a single transmembrane domain that forms pentameric ion channels, Virus Research. 201 (2015) 61-66. https://doi.org/10.1016/j.virusres.2015.02.023.

[46] P.P. Singh Tomar, I.T. Arkin, SARS-CoV-2 E protein is a potential ion channel that can be inhibited by Gliclazide and Memantine, Biochemical and Biophysical Research Communications. 530 (2020) 10-14. https://doi.org/10.1016/j.bbrc.2020.05.206.

[47] L. Wilson, P. Gage, G. Ewart, Hexamethylene amiloride blocks E protein ion channels and inhibits coronavirus replication, Virology. 353 (2006) 294-306. https://doi.org/10.1016/j.virol.2006.05.028.

[48] K. Pervushin, E. Tan, K. Parthasarathy, X. Lin, F.L. Jiang, D. Yu, A. Vararattanavech, T.W. Soong, D.X. Liu, J. Torres, Structure and Inhibition of the SARS Coronavirus Envelope Protein Ion Channel, PLOS Pathogens. 5 (2009) e1000511. https://doi.org/10.1371/journal.ppat.1000511.

[49] J. Torres, U. Maheswari, K. Parthasarathy, L. Ng, D.X. Liu, X. Gong, Conductance and amantadine binding of a pore formed by a lysine-flanked transmembrane domain of SARS coronavirus envelope protein, Protein Science. 16 (2007) 2065-2071. https://doi.org/10.1110/ps.062730007.

[50] V.S. Mandala, M.J. McKay, A.A. Shcherbakov, A.J. Dregni, A. Kolocouris, M. Hong, Structure and drug binding of the SARS-CoV-2 envelope protein transmembrane domain in lipid bilayers, Nat Struct Mol Biol. 27 (2020) 1202-1208. https://doi.org/10.1038/s41594-02000536-8.

[51] J. To, W. Surya, J. Torres, Chapter Eight - Targeting the Channel Activity of Viroporins, in: R. Donev (Ed.), Advances in Protein Chemistry and Structural Biology, Academic Press, 2016: pp. 307-355. https://doi.org/10.1016/bs.apcsb.2015.12.003.

[52] J.L. Nieva, V. Madan, L. Carrasco, Viroporins: structure and biological functions, Nature Reviews Microbiology. 10 (2012) 563-574. https://doi.org/10.1038/nrmicro2820.

[53] T. Jefferson, J. Deeks, V. Demicheli, D. Rivetti, M. Rudin, Amantadine and rimantadine for preventing and treating influenza A in adults, Cochrane Database of Systematic Reviews. (2004). https://doi.org/10.1002/14651858.CD001169.pub2.

[54] J.L. Nieto-Torres, C. Verdiá-Báguena, J.M. Jimenez-Guardeño, J.A. Regla-Nava, C. CastañoRodriguez, R. Fernandez-Delgado, J. Torres, V.M. Aguilella, L. Enjuanes, Severe acute respiratory syndrome coronavirus E protein transports calcium ions and activates the NLRP3 inflammasome, Virology. 485 (2015) 330-339. https://doi.org/10.1016/j.virol.2015.08.010.

[55] Y. Li, W. Surya, S. Claudine, J. Torres, Structure of a Conserved Golgi Complex-targeting Signal in Coronavirus Envelope Proteins, Journal of Biological Chemistry. 289 (2014) 1253512549. https://doi.org/10.1074/jbc.M114.560094.

[56] W. Surya, Y. Li, J. Torres, Structural model of the SARS coronavirus E channel in LMPG micelles, Biochimica et Biophysica Acta (BBA) - Biomembranes. 1860 (2018) 1309-1317. https://doi.org/10.1016/j.bbamem.2018.02.017. 
[57] S.J. Marrink, A.H. de Vries, D.P. Tieleman, Lipids on the move: Simulations of membrane pores, domains, stalks and curves, Biochim. Biophys. Acta. 1788 (2009) 149-168. https://doi.org/16/j.bbamem.2008.10.006.

[58] P. Buslaev, I. Gushchin, Effects of Coarse Graining and Saturation of Hydrocarbon Chains on Structure and Dynamics of Simulated Lipid Molecules, Scientific Reports. 7 (2017) 11476. https://doi.org/10.1038/s41598-017-11761-5.

[59] K.J. Boyd, N.N. Alder, E.R. May, Buckling Under Pressure: Curvature-Based Lipid Segregation and Stability Modulation in Cardiolipin-Containing Bilayers, Langmuir. 33 (2017) 6937-6946. https://doi.org/10.1021/acs.langmuir.7b01185.

[60] F. Elías-Wolff, M. Lindén, A.P. Lyubartsev, E.G. Brandt, Computing Curvature Sensitivity of Biomolecules in Membranes by Simulated Buckling, J. Chem. Theory Comput. 14 (2018) 1643-1655. https://doi.org/10.1021/acs.jctc.7b00878.

[61] S. Baoukina, H.I. Ingólfsson, S.J. Marrink, D.P. Tieleman, Curvature-Induced Sorting of Lipids in Plasma Membrane Tethers, Advanced Theory and Simulations. 1 (2018) 1800034. https://doi.org/10.1002/adts.201800034.

[62] J.J. Madsen, J.M.A. Grime, J.S. Rossman, G.A. Voth, Entropic forces drive clustering and spatial localization of influenza A M2 during viral budding, PNAS. 115 (2018) E8595-E8603. https://doi.org/10.1073/pnas.1805443115.

[63] R. Giri, T. Bhardwaj, M. Shegane, B.R. Gehi, P. Kumar, K. Gadhave, C.J. Oldfield, V.N. Uversky, Understanding COVID-19 via comparative analysis of dark proteomes of SARSCoV-2, human SARS and bat SARS-like coronaviruses, Cell. Mol. Life Sci. (2020). https://doi.org/10.1007/s00018-020-03603-X.

[64] S.H. Park, S.J. Opella, Tilt Angle of a Trans-membrane Helix is Determined by Hydrophobic Mismatch, Journal of Molecular Biology. 350 (2005) 310-318. https://doi.org/10.1016/j.jmb.2005.05.004.

[65] S.K. Kandasamy, R.G. Larson, Molecular Dynamics Simulations of Model Trans-Membrane Peptides in Lipid Bilayers: A Systematic Investigation of Hydrophobic Mismatch, Biophysical Journal. 90 (2006) 2326-2343. https://doi.org/10.1529/biophysj.105.073395.

[66] S. Özdirekcan, C. Etchebest, J.A. Killian, P.F.J. Fuchs, On the Orientation of a Designed Transmembrane Peptide: Toward the Right Tilt Angle?, J. Am. Chem. Soc. 129 (2007) 15174-15181. https://doi.org/10.1021/ja073784q.

[67] K.C. Duong-Ly, V. Nanda, W.F. DeGrado, K.P. Howard, The conformation of the pore region of the M2 proton channel depends on lipid bilayer environment, Protein Science. 14 (2005) 856-861. https://doi.org/10.1110/ps.041185805.

[68] R.B.M. Koehorst, R.B. Spruijt, F.J. Vergeldt, M.A. Hemminga, Lipid Bilayer Topology of the Transmembrane $\alpha$-Helix of M13 Major Coat Protein and Bilayer Polarity Profile by SiteDirected Fluorescence Spectroscopy, Biophysical Journal. 87 (2004) 1445-1455. https://doi.org/10.1529/biophysj.104.043208.

[69] A. Holt, J.A. Killian, Orientation and dynamics of transmembrane peptides: the power of simple models, Eur Biophys J. 39 (2010) 609-621. https://doi.org/10.1007/s00249-009-05671.

[70] T. Kim, W. Im, Revisiting Hydrophobic Mismatch with Free Energy Simulation Studies of Transmembrane Helix Tilt and Rotation, Biophysical Journal. 99 (2010) 175-183. https://doi.org/10.1016/j.bpj.2010.04.015.

[71] E. Strandberg, S. Esteban-Martín, A.S. Ulrich, J. Salgado, Hydrophobic mismatch of mobile transmembrane helices: Merging theory and experiments, Biochimica et Biophysica Acta (BBA) - Biomembranes. 1818 (2012) 1242-1249. https://doi.org/10.1016/j.bbamem.2012.01.023.

[72] R.N.P. Rodenburg, J. Snijder, M. van de Waterbeemd, A. Schouten, J. Granneman, A.J.R. Heck, P. Gros, Stochastic palmitoylation of accessible cysteines in membrane proteins revealed by native mass spectrometry, Nature Communications. 8 (2017) 1280. https://doi.org/10.1038/s41467-017-01461-z.

[73] M. Sarkar, S. Saha, Structural insight into the role of novel SARS-CoV-2 E protein: A potential target for vaccine development and other therapeutic strategies, PLOS ONE. 15 (2020) e0237300. https://doi.org/10.1371/journal.pone.0237300. 
[74] Y. Cao, R. Yang, W. Wang, I. Lee, R. Zhang, W. Zhang, J. Sun, B. Xu, X. Meng, Computational Study of the Ion and Water Permeation and Transport Mechanisms of the SARS-CoV-2 Pentameric E Protein Channel, Front. Mol. Biosci. 7 (2020). https://doi.org/10.3389/fmolb.2020.565797.

[75] H.T. McMahon, E. Boucrot, Membrane curvature at a glance, J Cell Sci. 128 (2015) 10651070. https://doi.org/10.1242/jcs.114454.

[76] T.R. Graham, M.M. Kozlov, Interplay of proteins and lipids in generating membrane curvature, Current Opinion in Cell Biology. 22 (2010) 430-436. https://doi.org/10.1016/j.ceb.2010.05.002.

[77] T. Baumgart, B.R. Capraro, C. Zhu, S.L. Das, Thermodynamics and Mechanics of Membrane Curvature Generation and Sensing by Proteins and Lipids, Annu. Rev. Phys. Chem. 62 (2011) 483-506. https://doi.org/10.1146/annurev.physchem.012809.103450.

[78] I.K. Jarsch, F. Daste, J.L. Gallop, Membrane curvature in cell biology: An integration of molecular mechanisms, Journal of Cell Biology. 214 (2016) 375-387. https://doi.org/10.1083/jcb.201604003.

[79] F. Campelo, H.T. McMahon, M.M. Kozlov, The Hydrophobic Insertion Mechanism of Membrane Curvature Generation by Proteins, Biophysical Journal. 95 (2008) 2325-2339. https://doi.org/10.1529/biophysj.108.133173.

[80] G. Drin, J.-F. Casella, R. Gautier, T. Boehmer, T.U. Schwartz, B. Antonny, A general amphipathic $\alpha$-helical motif for sensing membrane curvature, Nature Structural \& Molecular Biology. 14 (2007) 138-146. https://doi.org/10.1038/nsmb1194.

[81] H. Cui, E. Lyman, G.A. Voth, Mechanism of Membrane Curvature Sensing by Amphipathic Helix Containing Proteins, Biophysical Journal. 100 (2011) 1271-1279. https://doi.org/10.1016/j.bpj.2011.01.036.

[82] N.W. Schmidt, G.C.L. Wong, Antimicrobial peptides and induced membrane curvature: Geometry, coordination chemistry, and molecular engineering, Current Opinion in Solid State and Materials Science. 17 (2013) 151-163. https://doi.org/10.1016/j.cossms.2013.09.004.

[83] J.S. Rossman, X. Jing, G.P. Leser, R.A. Lamb, Influenza Virus M2 Protein Mediates ESCRTIndependent Membrane Scission, Cell. 142 (2010) 902-913. https://doi.org/10.1016/j.cell.2010.08.029.

[84] P.C.T. Souza, S. Thallmair, P. Conflitti, C. Ramírez-Palacios, R. Alessandri, S. Raniolo, V. Limongelli, S.J. Marrink, Protein-ligand binding with the coarse-grained Martini model, Nature Communications. 11 (2020) 3714. https://doi.org/10.1038/s41467-020-17437-5.

[85] W.G. Touw, C. Baakman, J. Black, T.A.H. te Beek, E. Krieger, R.P. Joosten, G. Vriend, A series of PDB-related databanks for everyday needs, Nucleic Acids Research. 43 (2015) D364-D368. https://doi.org/10.1093/nar/gku1028.

[86] W. Kabsch, C. Sander, Dictionary of protein secondary structure: Pattern recognition of hydrogen-bonded and geometrical features, Biopolymers. 22 (1983) 2577-2637. https://doi.org/10.1002/bip.360221211.

[87] T.A. Wassenaar, H.I. Ingólfsson, R.A. Böckmann, D.P. Tieleman, S.J. Marrink, Computational Lipidomics with insane: A Versatile Tool for Generating Custom Membranes for Molecular Simulations, J. Chem. Theory Comput. 11 (2015) 2144-2155. https://doi.org/10.1021/acs.jctc.5b00209.

[88] W.L. DeLano, The PyMOL molecular graphics system, (2002).

[89] T.A. Wassenaar, K. Pluhackova, R.A. Böckmann, S.J. Marrink, D.P. Tieleman, Going Backward: A Flexible Geometric Approach to Reverse Transformation from Coarse Grained to Atomistic Models, J. Chem. Theory Comput. 10 (2014) 676-690. https://doi.org/10.1021/ct400617g.

[90] S. Jo, T. Kim, V.G. Iyer, W. Im, CHARMM-GUI: A web-based graphical user interface for CHARMM, J. Comput. Chem. 29 (2008) 1859-1865. https://doi.org/10.1002/jcc.20945.

[91] M.J. Abraham, T. Murtola, R. Schulz, S. Páll, J.C. Smith, B. Hess, E. Lindahl, GROMACS: High performance molecular simulations through multi-level parallelism from laptops to supercomputers, SoftwareX. 1-2 (2015) 19-25. https://doi.org/10.1016/j.softx.2015.06.001.

[92] G. Bussi, D. Donadio, M. Parrinello, Canonical sampling through velocity rescaling, J. Chem. Phys. 126 (2007) 014101. https://doi.org/10.1063/1.2408420. 
[93] S. Nosé, A unified formulation of the constant temperature molecular dynamics methods, J. Chem. Phys. 81 (1984) 511-519. https://doi.org/10.1063/1.447334.

[94] M. Parrinello, A. Rahman, Polymorphic transitions in single crystals: A new molecular dynamics method, J. Appl. Phys. 52 (1981) 7182-7190. https://doi.org/10.1063/1.328693.

[95] Y. Atsmon-Raz, D.P. Tieleman, Parameterization of Palmitoylated Cysteine, Farnesylated Cysteine, Geranylgeranylated Cysteine, and Myristoylated Glycine for the Martini Force Field, J. Phys. Chem. B. 121 (2017) 11132-11143. https://doi.org/10.1021/acs.jpcb.7b10175.

[96] A.T. Shivgan, J.K. Marzinek, R.G. Huber, A. Krah, R.H. Henchman, P. Matsudaira, C.S. Verma, P.J. Bond, Extending the Martini Coarse-Grained Force Field to N-Glycans, J. Chem. Inf. Model. 60 (2020) 3864-3883. https://doi.org/10.1021/acs.jcim.0c00495.

[97] J. Huang, S. Rauscher, G. Nawrocki, T. Ran, M. Feig, B.L. de Groot, H. Grubmüller, A.D. MacKerell, CHARMM36m: an improved force field for folded and intrinsically disordered proteins, Nat. Methods. 14 (2017) 71-73. https://doi.org/10.1038/nmeth.4067.

[98] B. Hess, H. Bekker, H. Berendsen, J. Fraaije, LINCS: A linear constraint solver for molecular simulations, J. Comput. Chem. 18 (1997) 1463-1472. https://doi.org/10.1002/(sici)1096987x(199709)18:12\%3C1463::aid-jcc4\%3E3.0.co;2-h.

[99] D. Krause, P. Thörnig, JURECA: Modular supercomputer at Jülich Supercomputing Centre, Journal of Large-Scale Research Facilities JLSRF. 4 (2018) 132. https://doi.org/10.17815/jlsrf4-121-1.

[100] W. Humphrey, A. Dalke, K. Schulten, VMD Visual molecular dynamics, Journal of Molecular Graphics. 14 (1996) 33-38. https://doi.org/10.1016/0263-7855(96)00018-5.

[101] R.T. McGibbon, K.A. Beauchamp, M.P. Harrigan, C. Klein, J.M. Swails, C.X. Hernández, C.R. Schwantes, L.-P. Wang, T.J. Lane, V.S. Pande, MDTraj: A Modern Open Library for the Analysis of Molecular Dynamics Trajectories, Biophysical Journal. 109 (2015) 1528-1532. https://doi.org/10.1016/j.bpj.2015.08.015.

700

[102] V. Gapsys, B.L. de Groot, R. Briones, Computational analysis of local membrane properties, J Comput Aided Mol Des. 27 (2013) 845-858. https://doi.org/10.1007/s10822-013-9684-0. 
703 H2 observed in different simulations. See Figures 5 and 6 for definitions.

\begin{tabular}{|c|c|c|c|c|c|c|c|c|c|}
\hline Type & System & Lipid & $\begin{array}{c}\text { Mean } \\
\alpha,{ }^{\circ}\end{array}$ & $\begin{array}{c}\sigma_{-} \alpha, \\
。\end{array}$ & $\begin{array}{c}\text { Mean } \\
\beta,^{\circ}\end{array}$ & $\begin{array}{c}\sigma \_\beta, \\
。\end{array}$ & $\begin{array}{c}\text { Mean } \\
\varphi,^{\circ}\end{array}$ & $\Delta \varphi,^{\circ}$ & $\sigma_{-} \varphi,^{\circ}$ \\
\hline $\mathrm{CG}$ & No PTM & POPC & 26.9 & 8 & 34.1 & 29.4 & 77.7 & & 22.5 \\
\hline CG & CYSP40 & POPC & 26.6 & 8.9 & 34.7 & 31.2 & 85.4 & +7.7 & 20.5 \\
\hline $\mathrm{CG}$ & CYSP43 & POPC & 26.7 & 8.4 & 32.4 & 29 & 79.3 & +1.6 & 19.7 \\
\hline $\mathrm{CG}$ & CYSP44 & POPC & 27.1 & 8.3 & 40.3 & 28.8 & 106.6 & +28.9 & 19.1 \\
\hline $\mathrm{CG}$ & CYSP40/43 & POPC & 27.7 & 8.9 & 34.8 & 30.9 & 80.4 & +2.7 & 20.4 \\
\hline $\mathrm{CG}$ & CYSP40/44 & POPC & 26.1 & 8.6 & 42.9 & 26.5 & 109.9 & +32.2 & 19.6 \\
\hline CG & CYSP43/44 & POPC & 26.9 & 8 & 36.6 & 31.1 & 96.8 & +19.1 & 17.6 \\
\hline $\mathrm{CG}$ & CYSP40/43/44 & POPC & 26.4 & 8.3 & 31.2 & 30.4 & 103 & +25.3 & 17.2 \\
\hline $\mathrm{CG}$ & ASNG66 & POPC & 26.2 & 8.5 & 38.7 & 26.9 & 78.6 & +0.9 & 22.5 \\
\hline $\mathrm{CG}$ & TMD, no PTM & POPC & 25.5 & 7.7 & 29.4 & 31.4 & - & - & - \\
\hline $\mathrm{CG}$ & $\begin{array}{l}\mathrm{H} 2+\mathrm{H} 3, \\
\text { no PTM }\end{array}$ & POPC & - & - & - & - & 82.3 & +4.6 & 26.4 \\
\hline $\mathrm{AA}$ & No PTM & POPC & 40.2 & 9.9 & 48.1 & 22.6 & 85.3 & & 49.2 \\
\hline AA & No PTM & Mix & 32.6 & 11.6 & 50.5 & 27.2 & 83.7 & & 32.6 \\
\hline
\end{tabular}




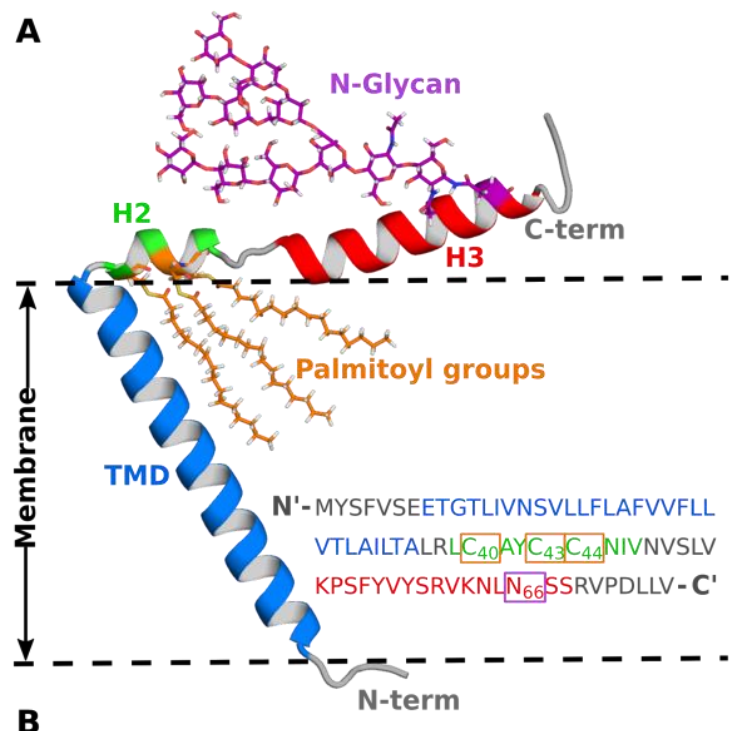

Figure 1. Structure of the SARS-CoV-2 envelope (E) protein monomer with possible post-

707 translational modifications. (A) Schematic model showing a fully palmitoylated and glycosylated E

708 protein. Transmembrane domain (TMD) is shown in blue and amphipathic helices $\mathrm{H} 2$ and $\mathrm{H} 3$ are shown

709 in green and red. (B) Conformations of the unmodified E protein observed in coarse-grained

710 simulations. Positions of the transmembrane helix were aligned for clarity; helices H2 and H3 are

711 mobile. 
A

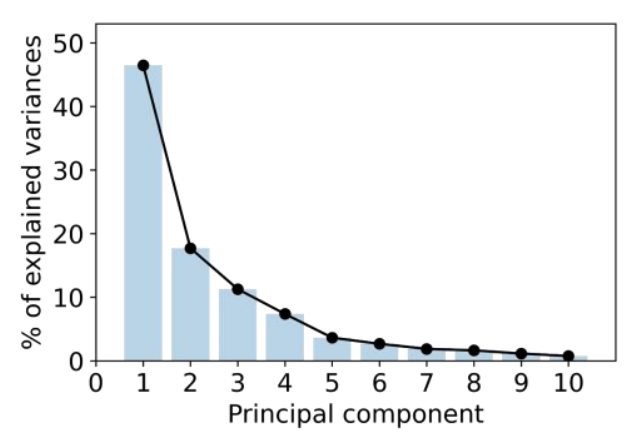

C

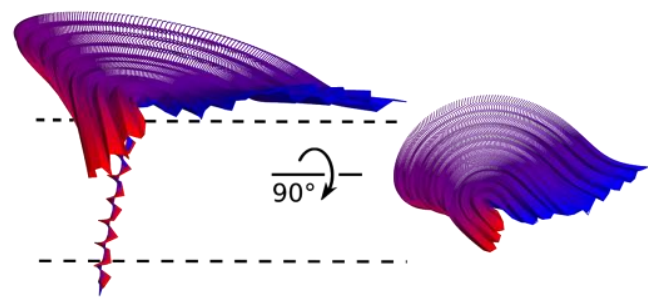

D
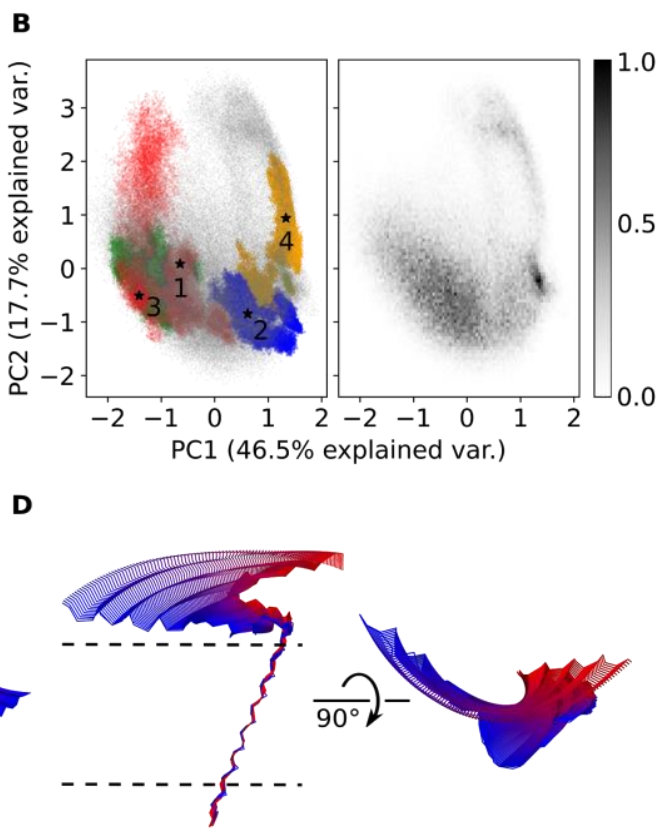

Figure 2. Comparison of the E protein conformations observed in atomistic and coarse-grained

714 simulations using principal component analysis. (A) The scree plot for the top ten PCA eigenvalues.

715 First two components describe $\sim 64 \%$ of structural variations. (B) Comparison of the conformational

716 ensembles observed in AA (colored) and CG (gray) simulations projected onto PC1 and PC2. The data

717 for CG simulations only are shown on the right. Starting conformations for AA simulations are shown

718 are labelled with stars. Trajectories from the first, second, third and fourth sets of AA simulations are

719 shown in red, blue, green and orange, respectively. (C) Conformational changes associated with PC1.

720 (D) Conformational changes associated with PC2. The structures are colored from blue to red according

721 to the PC projection value. Approximate membrane position is shown with lines. 


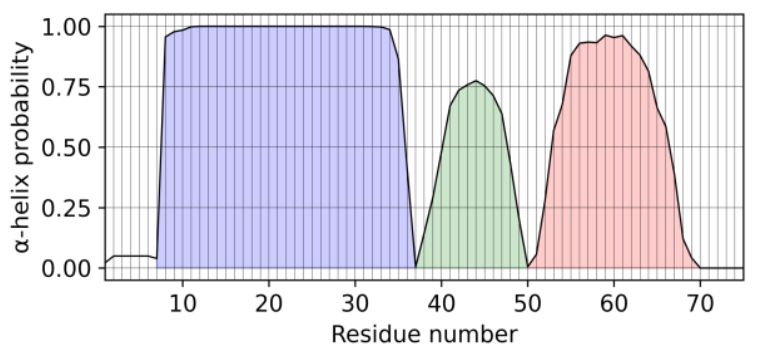

Figure 3. Conservation of the secondary structure of the E protein in AA MD simulations.

725 Average probability of observing the $\alpha$-helical structure for each residue is shown. TMD remains fully $\alpha$-helical, whereas $\mathrm{H} 2$ and $\mathrm{H} 3$ can be sometimes disordered (H2 more often compared to $\mathrm{H} 3$ ). 


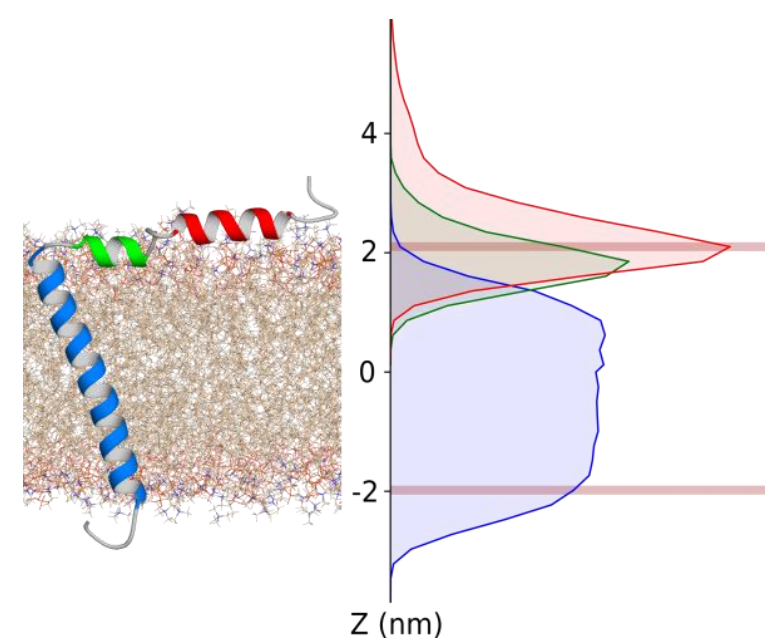

Figure 4. Average positions of $\mathrm{TMD}, \mathrm{H} 2$ and $\mathrm{H} 3$ relative to the membrane in all atom

730 simulations. Average positions of lipid phosphate groups are shown using brown lines. Distributions of

731 TMD, H2 and H3 backbone atoms' positions are shown in blue, green and red, respectively. 
A

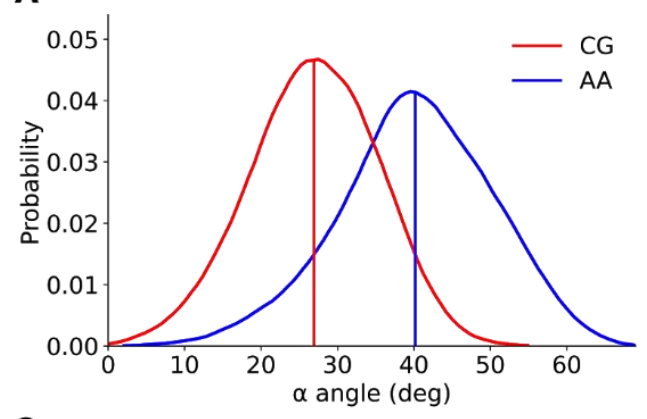

C

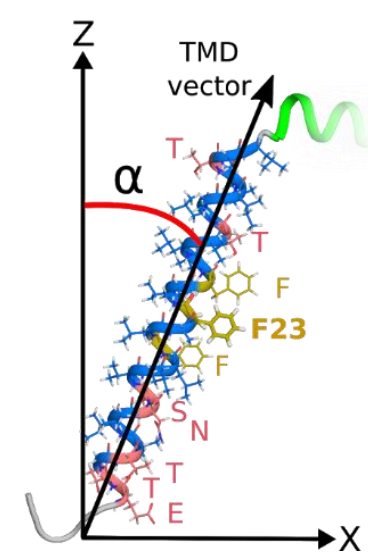

B

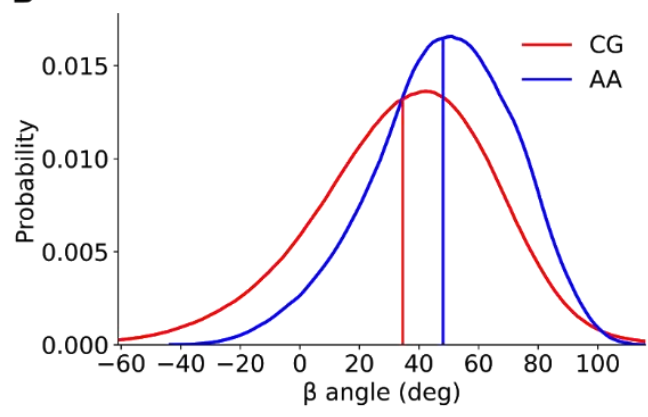

Figure 5. Orientation of TMD in POPC bilayer in coarse-grained (CG) and all atom (AA)

737 lines indicate average values. C) Definitions of the tilt $(\alpha)$ and axial rotation $(\beta)$ angles. 

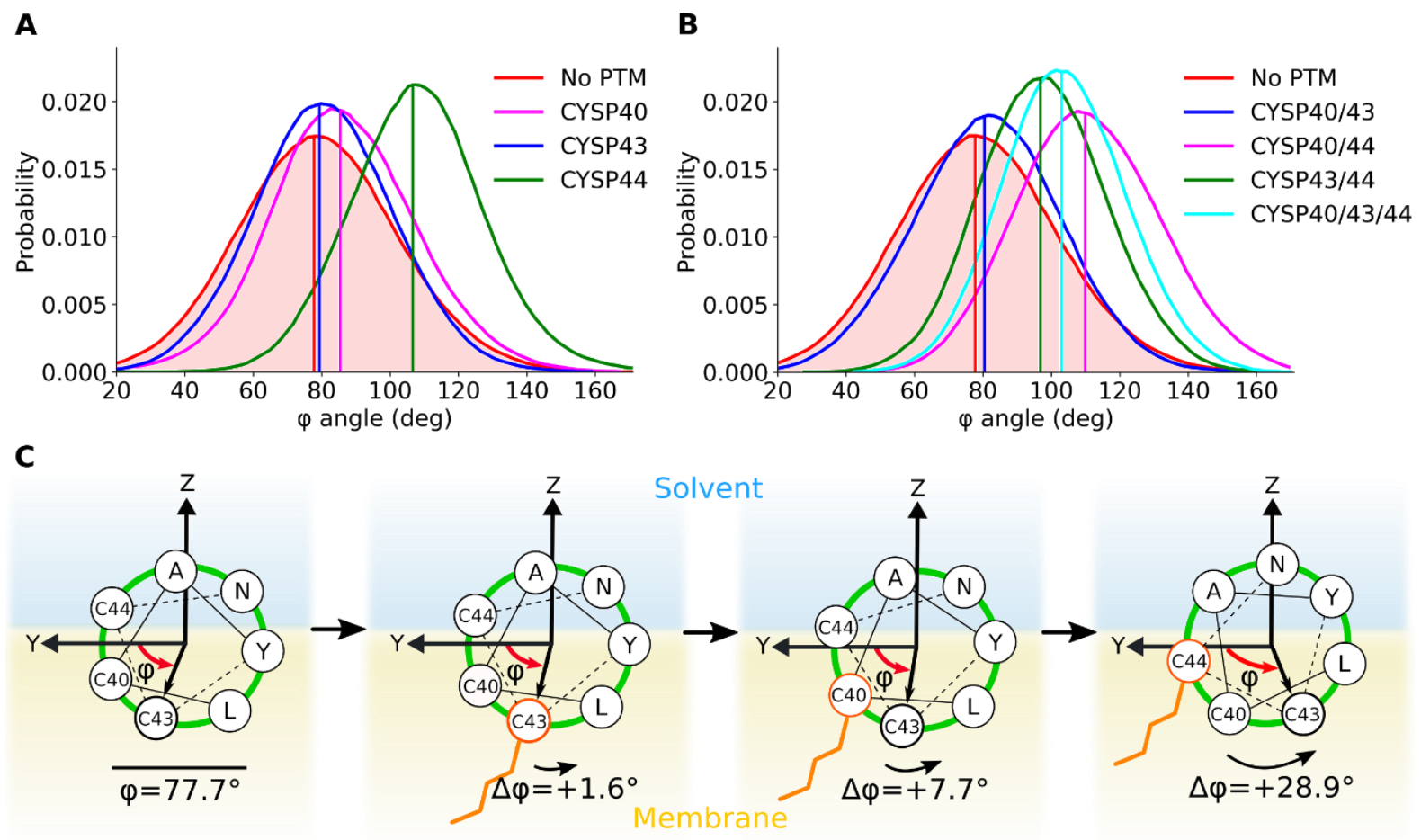

Figure 6. Effects of palmitoylation on orientation of the helix $\mathrm{H} 2$ relative to the membrane.

742 Rotation of Cys43 relative to the membrane plane (Y) viewed from the $\mathrm{N}$-terminus is analyzed. (A) and

743 (B) Distributions for the Cys43 rotation angles relative to the membrane plane for different PTMs.

744 Vertical lines indicate average values. (C) Schematics showing the H2 orientation with helical wheel

745 projections for selected variants. Palmitoylation affects the orientation of $\mathrm{H} 2$ because the respective 746 side chain becomes more hydrophobic. 
A

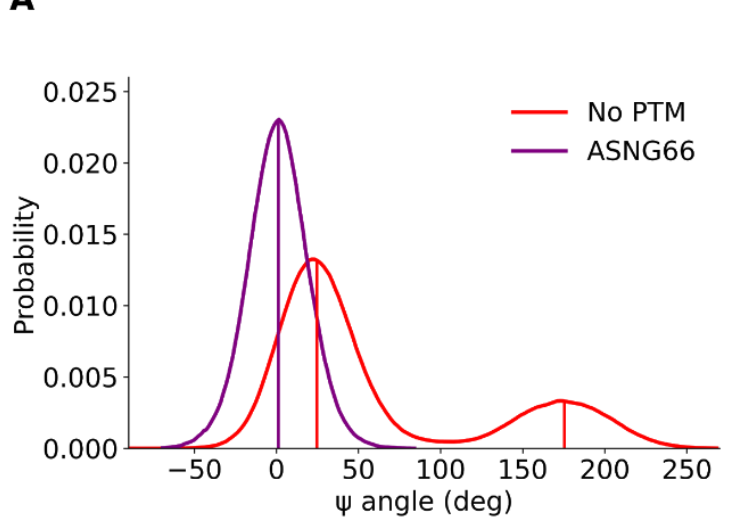

D

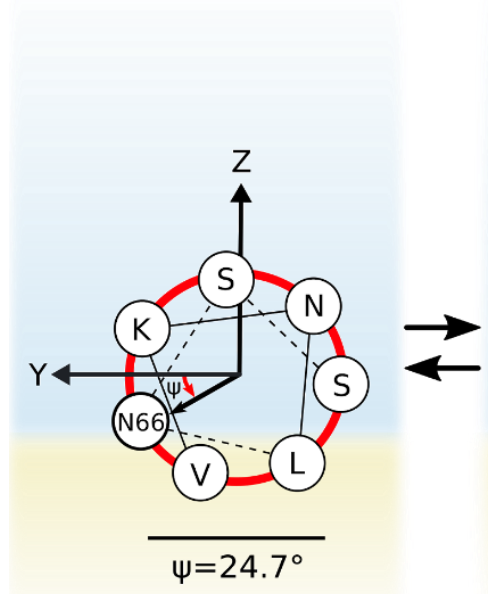

749

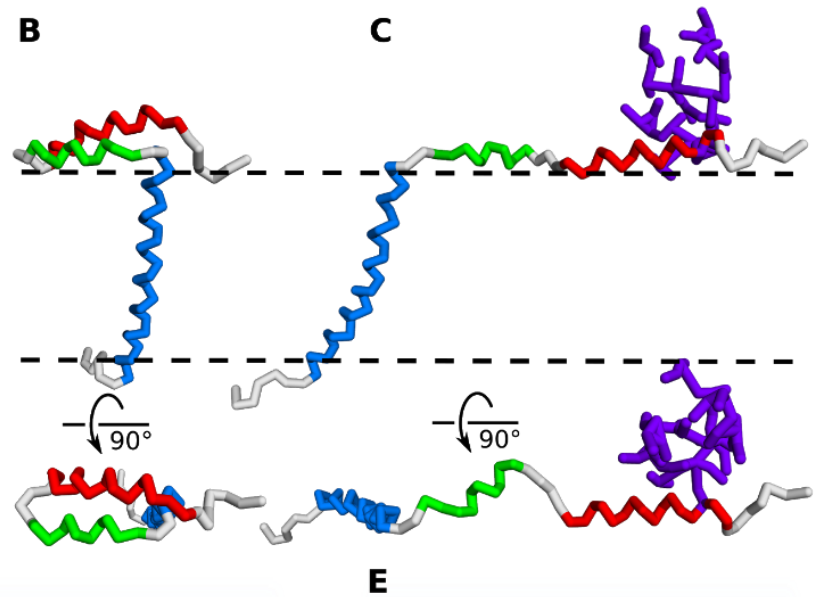

Solvent

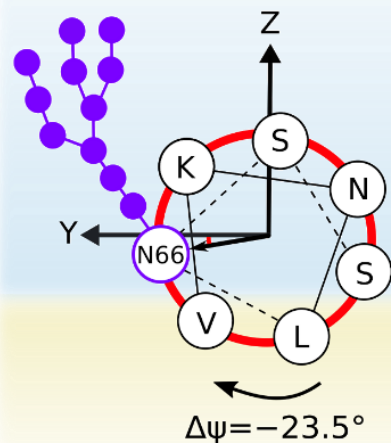

Figure 7. Effect of Asn66 glycosylation on orientation of the helix $\mathrm{H} 3$ relative to the membrane in coarse-grained simulations. Rotation of Asn66 relative to the membrane plane (Y) viewed from the N-terminus is analyzed. (A) Distributions for the Asn66 rotation angle relative to the membrane plane for unmodified and glycosylated variants. Vertical lines indicate average values. (B) and (C) Representative conformations for $\psi \approx 0^{\circ}$ and $\psi \approx 180^{\circ}$. (D) and (E) Schematics showing the H3 orientation with helical wheel projections for unmodified and glycosylated variants. Glycosylation of Asn66 precludes the configuration with $\psi=177^{\circ}$. 


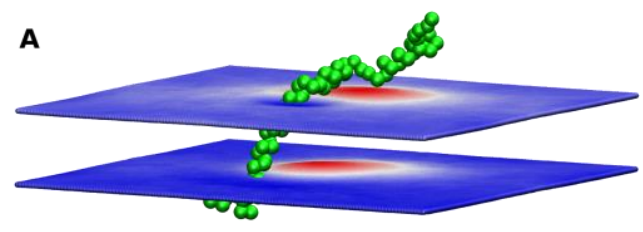

B

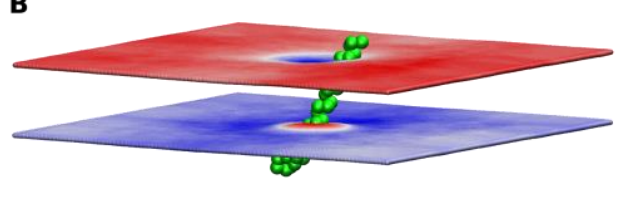

C

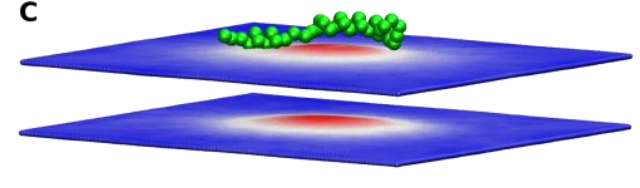

Figure 8. Induction of curvature by the E protein monomer in coarse grained simulations.

761 Upward displacement of each membrane boundary is shown in red, and downward displacement is shown in blue. (A) Induction of curvature by the full-length E protein. (B) Membrane deformation by an isolated TMD. The membrane is thinned around the TMD, but no buckling is observed. (C)

764 Membrane deformation by isolated $\mathrm{H} 2$ and $\mathrm{H} 3$ helices in coarse grained simulation. The membrane is

765 bent towards the $\alpha$-helices $\mathrm{H} 2$ and H3. Each panel shows an exemplary protein position; positions of

766 the membrane boundaries are averaged over the trajectory length. 
A
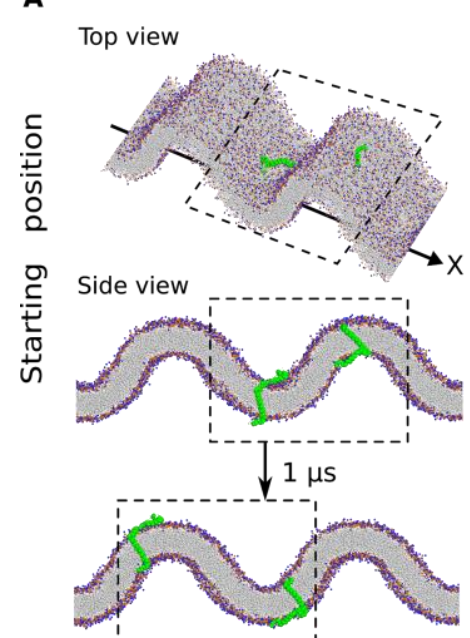
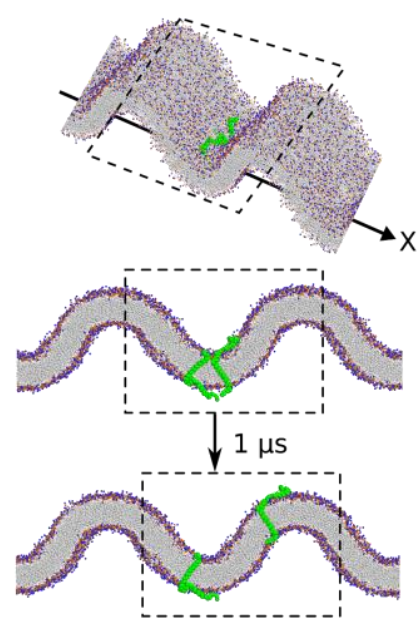

B
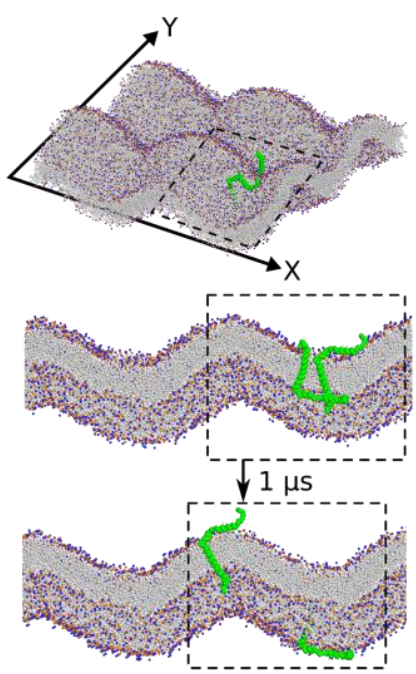

Figure 9. Monomeric E protein partitions into the curved region with the $\mathrm{N}$-terminus localizing

to the concave side independent of the starting position. (A) Simulations with the membrane buckled in 